\title{
When and Why Negative Emotional Appeals Work in Advertising: A Review of Research
}

\author{
Minxia Zheng \\ School of Management, Jinan University, Guangzhou, China \\ Email: zheng_minxia@126.com
}

How to cite this paper: Zheng, M. X. (2020). When and Why Negative Emotional Appeals Work in Advertising: A Review of Research. Open Journal of Social Sciences, $8,7-16$.

https://doi.org/10.4236/jss.2020.83002

Received: February 6, 2020

Accepted: March 3, 2020

Published: March 6, 2020

Copyright $\odot 2020$ by author(s) and Scientific Research Publishing Inc. This work is licensed under the Creative Commons Attribution International License (CC BY 4.0).

http://creativecommons.org/licenses/by/4.0/

(c) (i) Open Access

\begin{abstract}
This paper reviews theoretical and empirical evidence relating to the effectiveness of negative emotional advertising appeals in marketing. Through the review of research, it figures out when and why negative emotional appeals work in advertising. According to the research, the common negative emotions in advertisements are fear, guilt, sadness and anger. And the Elaboration Likelihood Model, Self-brand Connection Theory, Cognitive Dissonance Theory and so on are regarded as main explaining mechanisms of the effect. Further, the influence factors of the negative emotional appeals' effect are summarized, too. Finally, this paper presents the possible ideas in future research.
\end{abstract}

\section{Keywords}

Advertising Appeals, Negative Emotion, Explanation Mechanism, Influencing Factors

\section{Introduction}

Emotional Advertising is an important way for enterprises to attract consumers and promote their products. According to the valence of the advertising emotion, the emotional appeals are divided into positive emotional appeals and negative emotional appeals. Generally speaking, the valence of emotional advertising is positively related to the effect of the advertising. That is to say, positive emotional advertising (vs. negative emotional advertising) brings better advertising performances (Dens \& De Pelsmacker, 2010). However, there are also many research results show that conveying negative feelings in the advertisement turn out to bring positive advertising evaluation, product attitude and so on (Deborah \& Nicole, 2009).

Therefore, focusing on the question when and why negative emotional appeals 
work in advertising, this paper reviews previous research on negative emotional advertising appeals from five aspects: First of all, this paper clarifies the definition of negative emotional appeals in advertising. Secondly, it sorts out the main type of negative emotional appeals and clarifies their effects. Thirdly, it summarizes the underlying mechanism of their effectiveness. Fourthly, moderated factors among the research process are summed up. At last, it puts forward the future research directions.

\section{Definition}

Advertising appeal refers to displaying product's related information in a specific way, thereby attracting consumers' attention and persuading them to purchase (Park, Jaworski, \& Maclnnis, 1986). The emotional advertising appeal is one kind of advertising appeals, which stimulates the consumer's emotional attitude towards the product by adding emotion to the advertisement as well as creating the specific advertising image (Turley \& Kelley, 1997). Companies are able to express various types of emotions in advertising, such as humor, passion, sex, nostalgia, anger, and so on. Base on the valence of emotion, it can be split into positive emotion and negative emotion. Therefore, advertisements that express negative emotional advertising appeal are called as negative emotional advertisements.

\section{Different Negative Emotion Appeals' Effects}

Although consumer may have numerous negative emotions, marketers usually use 4 types of negative emotions in advertising: fear, guilt, sadness, and anger. Thus, this paper summarizes the effect of each above negative emotional appeals.

\subsection{Fear Appeals}

Fear is an emotional response people have when facing risks or crisis. In De Pelsmacker and Geuens's opinion, fear appeals are created by exposing consumers to all kinds of risks, including physical and social risks, time pressure, financial risks, product performance, and opportunity loss (De Pelsmacker \& Geuens, 1997).

Researchers claimed that fear appeals work like this: Firstly, by presenting some kind of threatening or frightening scene in the advertisement, fear appeal evokes consumers' nervous and uneasy emotions, along with the awareness of the potential negative consequences. Subsequently, the advertisement proposes an approach to deal with the threat (i.e. purchase the product), so that building trust with consumers, which can stimulate consumer purchase and satisfaction. For example, after seeing pictures of obese bodies in advertisements, participants increase their choice of healthy products for fear of obesity (Krishen \& Bui, 2015). What's more, Giachino et al. exposed 20 Italian students to a traffic advertisement with fear appeal, and monitored their driving behavior over a period of two months. This paper demonstrated the efficacy of fear-based advertise- 
ments in reducing high-speed driving (Giachino, Stupino, Petrarulo, \& Bertoldi, 2017).

\subsection{Guilt Appeals}

When a consumer's decision violates his or her personal value judgment or social norms, a negative emotion is generated, called a sense of guilt (Burnett \& Lunsford, 1994). Dedeoglu et al. pointed out that wrong actions, non-actions, breaches of norms, failure of self-control, and indulgence of pleasure were all able to inspire consumers' sense of guilt (Dedeoglu \& Kazancoglu, 2010). Yi and Baumgartner further divided consumer guilt into financial guilt, health guilt, moral guilt, and social responsibility guilt (Yi \& Baumgartner, 2011).

It is quite common that marketers apply guilt as an emotional appeal to advertisements. By using guilt appeal, advertisements stimulate consumers to create anxiety, self-blame, guilt and other negative feelings, so as to guide them to comply with the advertisements' advice, make purchasing decisions, thereby repairing their psychological imbalance. Durkin et al. figured out that sense of guilt reduces participants' consumption of junk food (i.e. chocolate) (Durkin, Rae, \& Stritzke, 2012). Lwin and Phau's research showed that guilt appeals in charitable advertisements improve consumers' willingness to donate (Lwin \& Phau, 2014).

\subsection{Sadness Appeals}

Associated with negative events, sadness is an emotional response when people suffer from separation, loss and failure. Based on scholars' research results, using sadness appeals in advertising is proven to cause empathy and emotional immersion. According to Roozen, commercial that contains sadness appeals works better for commercials and proves to be the most responsive for the for-profit brands. Small and Verrochi found that appeals painting victims with a sad (vs. happy or neutral) facial expression, which had a higher possibility to promote participants' sympathy, were more effective at arising donating behavior (Small \& Verrochi, 2009). Furthermore, anti-tobacco advertisements eliciting strong negative emotions (i.e. sadness and fear) were rated most effectively by respondents (Biener, McCallum-Keeler, \& Nyman, 2000).

\subsection{Anger Appeals}

If someone's goals, especially those related to self-protection seem to be threatened or failed, he or she will be easy to be angry. According to the Anger Activism Model, anger can affect person's cognition. The functions of anger appeals in advertising are to stimulate people to hold or regain control of specific occasions. Therefore, through using anger appeals, advertisements reveal that something is wrong in the situation, and motivate people to take actions to remove barriers of goal achievement. That is to say, guiding consumers to trust and choose the products in the advertisements. For example, Ilakkuvan et al. empha- 
sized that consumers were more possible to be persuaded and receptive to the anti-smoking advertisement added angry appeals (Ilakkuvan, Turner, Cantrell, Hair, \& Vallone, 2017). When selling products linked to consumers' certain goal achievements, such as health-promoting fitness equipment, marketers are advised to utilize anger appeals in advertisement to motivate consumers' purchase intensions.

\section{Explanation Mechanism}

Through reviewing scholars' research, this paper summarizes the main theories and mechanisms that widely used to explain the effect of negative emotional appeals.

\subsection{The Elaboration Likelihood Model}

It is consensus that the way how consumers process advertising information will affect their attitudes to advertising. The Elaboration Likelihood Model is a powerful and effective model to explain consumers' information process. According to the Elaboration Likelihood Model, advertising has two paths of persuasion to consumers when they process information on advertising appeals, including the central route and the peripheral route (Petty, Heesacker, \& Hughes, 1997). Adopting the central route, consumers will carry out detailed information processing, integrate and analyze multifaceted information from the advertisement. After that, they will form their product judgment. Differently, consumers who use the peripheral route may not be motivated by the performance of the product itself, but through the association and experience of the advertisement to generate their product attitude.

Pallak argued that advertising appeals are closely related to processing route. When dealing with cognitive information, consumers activate the central route, while facing emotional information, the peripheral one works (Pallak, 1983). That is to say, in the face of emotional appeals, consumers rely on emotional experience, heuristic inference, and affect transfer to process advertising information. This path is commonly considered to be the internal mechanism how emotional appeals influence consumers' purchase intention, product valuation and brand attitude. Therefore, the consumer's information processing routes help to explain why negative emotion appeals gain positive advertising effect.

\subsection{Self-Brand Connection Theory}

Besides above angle of information processing, scholars also explained the effect through the angle of the connection between consumers and brands. According to the self-brand connection theory, consumers are likely to compare their own personality and brand personality when choosing a product. Johar and Sirgy found that consumers' processing mechanism of emotional advertising is selfconsistency (Johar \& Sirgy, 1991). Self-consistency refers to the consistency between consumer's self-image, self-personality and product users' image, along 
with product personality in the advertisement. Advertising with emotional appeal convinces consumers by influencing them to match the product emotion and self-emotion. If the self-brand consistency is great, the target consumer will be satisfied with the brand and easy to be persuaded by the advertisement. Research by Hong and Zinkhan showed that the better match between the emotional appeal of advertising and self-emotional appeal (i.e. the higher self-brand consistency), the higher the willingness to purchase, the better the brand attitude (Hong \& Zinkhan, 1995). Detailedly speaking, negative emotional advertising appeals build specific connection between consumers and brands, make consumers aware of their emotional consistence.

\subsection{Cognitive Dissonance Theory}

The theory of cognitive dissonance is a kind of attitude change theory put forward by American social psychologist Festinger, which refers to the individual's own recognition of the contradiction between his or her attitude, or between attitude and behavior (Festinger, 1962). In general, he argues, individual attitudes and behaviors toward things are coordinated.

However, negative emotion may induce peoples' cognitive dissonance. For instance, the "tragic" advertisements describing the misfortune of victims are inconsistent with people's perception of good life. And according to cognitive dissonance theory, when incongruity occurs, cognitive disharmony occurs, i.e. cognitive dissonance, which can lead to individual tension. And for the purpose of relieving stress, individuals try to regain cognitive balance by consciously changing cognition, adding new cognition, changing the relative importance of cognition, changing behavior, and so on. Thus, when suffering cognitive dissonance induced by the negative emotional appeals, consumers tend to follow the solutions suggested in the advertisements to reduce inconsistencies to gain cognitive coordination and psychological balance. For example, participants become more willing to donate to victims. Krishen and Bui further demonstrated that being exposed to advertising picture of obesity body, which will disturb participants' awareness of fitness, participants are more likely to purchase the healthy food out of their fear (Krishen \& Bui, 2015).

\subsection{Empathy}

Consumers' positive advertising attitude often stem from agreements of advertising content. That is to say, those advertisements that can arouse consumers' empathy, are more possible to win their affections. Empathy means that individuals identify with the feelings and mood of external others. Specifically, it refers to the resonance between consumer's emotional appeals and the advertisement's emotional appeals. That is to say, the perception of self-emotion and advertising emotion is consistent. Many brands set up the aim to create proper content in advertisements that really echo with consumers. Through emotional resonance, empathy was demonstrated as a powerful response that attempts and 
acknowledges to understand individual's suffering (Sinclair, Beamer, Hack, McClement, Bouchal, \& Chochinov, 2017). For enterprises, empathy can be used in creating the image of the customer, or performing the scenes they have been through in real life. And by describing contents that elicit empathy, consumers are more likely to take action, i.e. buying, sharing. More specifically, negative emotional appeals are beneficial to enhance participants' empathy towards the advertising, since it shows the similar, even the same negative emotional feelings as consumers'.

\subsection{Conditional Reflection Theory}

Conditional reflection means when the target object is stimulated, the stimulus object will show a corresponding reaction. Advertisers adopt appropriate advertising strategies to stimulate the target consumers, induce their response to the advertisements and purchase behavior. When a brand's product is combined with the corresponding stimulus, it will create a relationship between a particular emotional response and a particular brand product. Obviously, the different emotional stimuli of advertising can cause consumers to respond to different emotional response. Moreover, consumers may gradually have a specific feeling about the product and brand itself. Hence, negative emotional appeals in advertising can form a specific reflection. That is to say, the advertisements and products may occur in consumers' mind when they experience the same negative emotion and advertising situations.

\section{Moderated Factors}

The main factors moderated the effect of negative emotional appeals are divided into 2 types as follows.

\subsection{Advertising Objects}

On the one hand, subjects of advertising influence the usage of advertising appeals. Different advertising appeals are suitable for different orientations of advertisements. For instance, social cause advertisements elicited more emotional appeals than profit-oriented advertisements, while profit-oriented advertisements conveyed more information content (Sciulli \& Bebko, 2005). Commercial advertising and public service advertising also demand for different advertising appeals. Negative emotional appeals are more often used in charities advertisements.

On the other hand, the product types the advertisement aims for also moderate the effect of negative emotional advertising appeals. For example, considering that hedonistic products are designed to arouse consumers' interest in experience and enjoyment, advertisement for hedonistic products can trigger a more positive advertising effect by emotional appeals. On the contrary, when consumers are processing advertising for utilitarian product, they usually focus on the information about quality, price, functions, and so on. In that case, using 
negative emotional appeals may not be easy to attract their attentions.

\subsection{Individual Factors}

Affect intensity is the magnitude of strength when people experience their emotions. Though facing the same things, peoples' affect intensity may be different. In addition, the Affect Intensity Measurement scale is widely used to measure participants' affect intensity among empirical research. Previous research has declared that different affect intensity among consumers may bring big variations in their response to emotional advertising appeals. In other words, consumers' attitudes and action tendencies towards negative emotional advertising appeals are moderated by their affect intensity.

Gender differences affect the effectiveness of emotional appeal. Females showed more favorable attitude towards helping when exposed to the sad emotional appeal advertisement than the rational appeal advertisement, while males showed no significant differences in attitude to help in the two conditions (Wang, 2008).

Consumers at different ages hold diverse attitudes towards emotional appeals in advertising. Mather and Carstensen had repeatedly shown that a "positivity bias" exists in older adults. For the old, positive emotions become more prominent and negative ones become less prominent. Therefore, negative emotional appeals in advertisement are more difficult to gain satisfaction from the old (Mather \& Carstensen, 2005).

Social identities are associated with consumers' preference for negative emotional appeals. Consumers enjoy the emotional appeals in advertisements, which are consistent with their salient social society. Specifically, participants with a salient athlete identity (vs. volunteer identity, environmentalist identity) have more adorable evaluations to an anger (vs. sad, disgusting) advertisement (Coleman \& Williams, 2013).

\section{Discussion and Future Research}

This paper has discussed the current research results of negative emotional appeals in advertising, including definition, emotion types, mechanisms of effect, and influence factors. After that, the following research directions are worth exploring in the future.

Firstly, compared to charities advertising, the study of negative emotional appeal in commercial advertising is still not sufficient. Researchers mainly investigate the fear appeals in advertisements of healthy food or weight-loss products. In marketing scenes, there are still lots of products including negative appeals in commercial advertisement. For example, advertisements for game products depict the coldness of the real world, dating software like to exaggerate loneliness if users don't have social relationships. Based on these phenomenon, future research should pay attention to more commercial advertisements with more types of negative emotions.

Secondly, as mentioned earlier, previous research generally focuses on 4 nega- 
tive emotions, i.e. fear, guilt, sadness, and anger. However, many negative emotions still lack fundamental research, like being alarmed, frightened, worried, depressed, lonely, anxious, shamed, regret and so on. For example, social anxiety, the worry or expectation about negative social evaluation from others, may result in one's feelings of inferiority and inadequacy. Thus, social anxiety appeals in direct-to-consumer advertisements encourage patients to adopt the advertised treatment program (Good \& Huhmann, 2018). As a result, further research should be concerned with above new negative emotional appeals in advertising to enrich and develop research extent.

Finally, marketing scholars should notice that the level of emotion is possible to influence consumers' advertising attitude. First of all, it is necessary to ensure enough emotional strength so that the advertisement has the opportunity to attract consumers' attention and emotional resonance. Moreover, the relationship between negative emotional appeals and advertising affect is not simple linear. In particular, Jimenez and Yang proved that participants made more favorable evaluation of the green advertisement and brand when exposed to a low guilt advertisement than to a high guilt one (Jimenez \& Yang, 2008). Cotte et al. pointed out that a high level of guilt could increase consumer anger, which in turn to the sense of manipulation from the advertisement, and turned out to be harmful to the persuasiveness of advertising (Cotte, Coulter, \& Moore, 2005). It is significant to conduct relevant research to grasp the suitable emotion level of each negative emotional appeals.

\section{Conflicts of Interest}

The author declares no conflicts of interest regarding the publication of this paper.

\section{References}

Biener, L., McCallum-Keeler, G., \& Nyman, A. L. (2000). Adults' Response to Massachusetts Anti-Tobacco Television Advertisements: Impact of Viewer and Advertisement Characteristics. Tobacco Control, 9, 401-407. http://dx.doi.org/10.1136/tc.9.4.401

Burnett, M. S., \& Lunsford, D. A. (1994). Conceptualizing Guilt in the Consumer Decision-Making Process. Journal of Consumer Marketing, 11, 33-43. http://dx.doi.org/10.1108/07363769410065454

Coleman, N. V., \& Williams, P. (2013). Feeling Like Myself: Emotion Profiles and Social Identity. Journal of Consumer Research, 40, 203-222. https://www.jstor.org/stable/10.1086/669483

Cotte, J., Coulter, R., \& Moore, M. (2005). Enhancing or Disrupting Guilt: The Role of Credibility and Perceived Manipulative Intent. Journal of Business Research, 58, 361-368. https://doi.org/10.1016/S0148-2963(03)00102-4

De Pelsmacker, P., \& Geuens, M. (1997). Emotional Appeals and Information Cues in Belgian Magazine Advertisements. International Journal of Advertising, 16, 123-147. https://doi.org/10.1111/j.0265-0487.1997.00049.pp.x

Deborah, A. S., \& Nicole, M. V. (2009). The Face of Need: Facial Emotion Expression on Charity Advertisements. Journal of Marketing Research, 46, 777-787. 
https://www.jstor.org/stable/20618940

Dedeoglu, A. O., \& Kazancoglu, L. (2010). The Feelings of Consumer Guilt: A Phenomenological Exploration. Journal of Business, Economics and Management, 11, 462-482. http://dx.doi.org/10.3846/jbem.2010.23

Dens, N., \& De Pelsmacker, P. (2010). Consumer Response to Different Advertising Appeals for New Products: The Moderating Influence of Branding Strategy and Product Category Involvement. Journal of Brand Management, 18, 50-65. http://dx.doi.org/10.1057/bm.2010.22

Durkin, K., Rae, K., \& Stritzke, W. G. K. (2012). The Effect of Images of Thin and Overweight Body Shapes on Women's Ambivalence towards Chocolate. Appetite, 58, 222-226. https://doi.org/10.1016/j.appet.2011.09.027

Festinger, L. (1962). Cognitive Dissonance. Scientific American, 207, 93-102, http://www.nature.com/doifinder/10.1038/scientificamerican1062-93

Giachino, C., Stupino, M., Petrarulo, G., \& Bertoldi, B. (2017). Fear Appeals in Social Marketing: The Case of Anti-Speeding Video Advertisement "Mistakes". Journal of Customer Behaviour, 16, 61-74. http://dx.doi.org/10.1362/147539217X14909732699480

Good, M. C., \& Huhmann, B. A. (2018). Social Relationships and Social Anxiety Appeals in Direct-to-Consumer Advertising. Journal of Marketing Communications, 24, 393-411. https://doi.org/10.1080/13527266.2018.1432499

Hong, J. W., \& Zinkhan, G. M. (1995). Advertising Effectiveness: The Influence of Congruency, Conspicuousness, and Response Mode. Psychology and Marketing, 12, 53-77. https://doi.org/10.1002/mar.4220120105

Ilakkuvan, V., Turner, M. M., Cantrell, J., Hair, E., \& Vallone, D. (2017). The Relationship between Advertising-Induced Anger and Self-Efficacy on Persuasive Outcomes. Family and Community Health, 40, 72-80. http://doi.org/10.1097/FCH.0000000000000126

Jimenez, M., \& Yang, K. C. (2008). How Guilt Level Affects Green Advertising Effectiveness? Journal of Creative Communications, 3, 87-88. https://doi.org/10.1177/097325861000300301

Johar, J. S., \& Sirgy, M. J. (1991). Value-Expressive versus Utilitarian Advertising Appeals: When and Why to Use Which Appeal. Journal of Advertising, 10, 23-33. https://www.jstor.org/stable/4188804

Krishen, A. S., \& Bui, M. (2015). Fear Advertisements: Influencing Consumers to Make Better Health Decisions. International Journal of Advertising, 34, 533-548. https://doi.org/10.1080/02650487.2014.996278

Lwin, M., \& Phau, I. (2014). An Exploratory Study of Existential Guilt Appeals in Charitable Advertisements. Journal of Marketing Management, 30, 1467-1485. https://doi.org/10.1080/0267257X.2014.939215

Mather, M., \& Carstensen, L. L. (2005). Aging and Motivated Cognition: The Positivity Effect in Attention and Memory. Trends in Cognitive Sciences, 9, 496-502. https://doi.org/10.1016/j.tics.2005.08.005

Pallak, S. (1983). Salience of Communicator's Physical Attractiveness and Persuasion: Heuristic versus Processing Information. Social Cognition, 2, 158-170. https://guilfordjournals.com/doi/10.1521/soco.1983.2.2.158

Park, C. W., Jaworski, B. J., \& Maclnnis, D. J. (1986). Strategic Brand Concept-Image Management. Journal of Marketing, 50, 135-145. https://www.jstor.org/stable/1251291

Petty, R. E., Heesacker, M., \& Hughes, J. N. (1997). The Elaboration Likelihood Model: Implications for the Practice of School Psychology. Journal of School Psychology, 35, 
107-136. https://doi.org/10.1016/S0022-4405(97)00003-4

Sciulli, L. M., \& Bebko, C. (2005). Social Cause versus Profit Oriented Advertisements. Journal of Promotion Management, 11, 17-36. http://dx.doi.org/10.1300/J057v11n02_03

Sinclair, S., Beamer, K., Hack, T. F., McClement, S., Bouchal, S. R., \& Chochinov, H. M. (2017). Sympathy, Empathy, and Compassion: A Grounded Theory Study of Palliative Care Patients' Understandings, Experiences, and Preferences. Palliative Medicine, 31, 437-447. https://doi.org/10.1177/0269216316663499

Small, D. A., \& Verrochi, N. M. (2009). The Face of Need: Facial Emotion Expression on Charity Advertisements. Journal of Marketing Research, 46, 777-787.

https://www.jstor.org/stable/20618940

Turley, L. W., \& Kelley, S. W. (1997). A Comparison of Advertising Content: Business to Business versus Consumer Services. Journal of Advertising, 26, 39-48.

https://www.jstor.org/stable/4189049

Wang, C. L. (2008). Gender Differences in Responding to Sad Emotional Appeal: A Moderated Mediation Explanation. Journal of Nonprofit and Public Sector Marketing, 19, 55-70. https://doi.org/10.1300/J054v19n01_03

Yi, S., \& Baumgartner, H. (2011). Coping with Guilt and Shame in the Impulse Buying Context. Journal of Economic Psychology, 32, 458-467.

http://dx.doi.org/10.1016/j.joep.2011.03.011 